\title{
Birthweight and subsequent growth of children exposed to rubella infection in utero
}

\author{
H. LEJARRAGA and CATHERINE S. PECKHAM \\ From the Department of Growth and Development, Institute of Child Health; and the Department of \\ Microbiology, The Hospital for Sick Children, London
}

\begin{abstract}
Lejarraga, H., and Peckham, C. S. (1974). Archives of Disease in Childhood, 49, 50. Birthweight and subsequent growth of children exposed to rubella infection in utero. Birthweight, and head circumference and body weight at preschool age were studied in a group of 212 children exposed to maternal rubella infection. Birthweights were compared to standards for birthweights of British children according to gestational age and birth rank. Children with detectable rubella antibody at the time of the examination were regarded as seropositive and those with no detectable antibody as seronegative. It was shown that the mean birthweight of seronegative and seropositive children without rubella defects did not differ significantly from the 50th centile or from each other, but that those who were seropositive with defects had significantly lower birthweights. Head circumference and body weight were similarly compared to current British standards. Head circumference at follow-up was normal in seronegative and seropositive children without defects, but significantly low in seropositive children with defects, even if retinopathy was the sole defect. The findings for body weight at follow-up were similar, reflecting absence of catch-up growth in weight in the children with congenital rubella defects.

This study has shown that intrauterine growth retardation does not present as the sole manifestation of maldevelopment in congenital rubella.
\end{abstract}

In a follow-up study of children whose mothers had had rubella infection during pregnancy the birthweights of children with rubella antibody but without congenital defects were found to be normal (Peckham, 1972). However, the birthweight standards used made no allowance for differences in sex or for the differences associated with birth order. The data have therefore been analysed again using more accurate birthweight standards, and in addition the body weight and head circumference of these children at follow-up in the preschool period were measured.

\section{Material and methods}

The children were born to women who developed rubella during pregnancy and who had been given immunoglobulin in a prospective study carried out by the Public Health Laboratory Service between 1956 and 1962 (McDonald and Peckham, 1967). It was possible to measure 212 of these children during the preschool period. Their clinical and laboratory characteristics

Received 16 July 1973. have been fully described in a previous report (Peckham, 1972). The diagnosis of rubella in the mothers was made on clinical grounds, and the postmenstrual age at the time of the appearance of the rubella rash was available in the majority of cases. A diagnosis of congenital rubella infection in the children was made when rubella neutralizing antibody was present in the serum between the ages of 1 and 4 years (Dudgeon, Butler, and Plotkin, 1964).

Information concerning birthweight was provided by the child's doctor shortly after the birth. The birthweights of 212 children were compared to standards for birthweight for British children (Tanner and Thomson, 1970) according to gestational age, sex, and birth order. Patients in whom the gestational age was not known were not included in the study of birthweight; those in whom no birth order was available were excluded from the calculations, though their birthweights were plotted on the charts.

Body weight was recorded for 159 children and head circumference was measured in 154 children, at The Hospital for Sick Children, Great Ormond Street, and at other hospitals, when the children were between the ages of 1.8 years and 6 years $(96 \%$ were within the range 1.9 
to 4 years). The values for weight and head circumference were compared to standards for British children (Tanner, Whitehouse, and Takaishi, 1966; J. M. Tanner and R. H. Whitehouse, unpublished data).

All measurements are expressed in terms of Standards Deviation Scores (SDS) according to the formula $\mathrm{SDS}=\mathrm{x}-\overline{\mathrm{x}} / \mathrm{SD}$, where $\mathrm{x}$ is the measurement, $\overline{\mathrm{x}}$ is the mean from the standards (50th centile) at the relevant age, and SD the standard deviation at that age. In a normal population the mean SDS should be equal to zero and the SD equal to one.

\section{Results}

The sample of 212 patients was divided into three groups according to the following criteria.

Group A. 97 children who had escaped congenital rubella infection as they were without detectable rubella neutralizing antibody (seronegative) and had no evidence of congenital rubella defects. This provided an optimal control group. Mean age at follow-up was $2 \cdot 7$ years, SD $0 \cdot 6$.

Group B. 71 children who were seropositive but had no detectable manifestations of congenital rubella at the time of follow-up. Mean age was $2 \cdot 7$ years, SD 0.6 .

Group C. 44 seropositive children with congenital rubella defects. The defects in this group of children consisted predominantly of bilateral deafness with or without retinopathy, there being only two heart defects, one CNS defect, and no cataracts. Mean age at follow-up was 2.5 years, SD $0 \cdot 5$.

The mean gestational ages of children in groups $\mathrm{A}, \mathrm{B}$, and $\mathrm{C}$ were $39.99,39.97$, and 39.87 weeks, respectively. The incidence of preterm babies was not higher than would be expected in a normal population in any of the groups. The distribution of birth ranks was not significantly different in seropositive and seronegative children.

Birthweights of 111 boys and girls from groups $B$ and $\mathrm{C}$ were plotted on the standard charts in the Fig. (for the purpose of the Fig. birthweights are all corrected to a birth rank of later born, and so should be read against the later-born lines). One seropositive patient born after 44 weeks' gestation (birthweight $3515 \mathrm{~g}$ ) has not been plotted. Children with retinopathy as the sole detectable defect were plotted separately as solid triangles. The percentage of children with rubella defects and birthweight below the 50th centile was greater than the percentage below the 50th centile of those without defects.

In the Table the means, standard errors (SE), and standard deviations (SD) for birthweight, head circumference, and weight SDS at follow-up are recorded for the 3 groups of patients. None of the mean values for groups $A$ and $B$ was significantly different from zero or from each other $(P>0.2)$, except mean weight SDS of group A. However, children with congenital rubella malformations (group C) had significantly lower values in all three measurements.

Group C was further split into three subgroups according to the presence of retinopathy or deafness as sole defects, or multiple malformations. In children with retinopathy only, body weight was not affected either at birth or at follow-up, though the head circumference was significantly lowered. Time of appearance of maternal rash in this subgroup ranged from the 8th to the 17th week. Children with deafness only did not significantly differ from children with multiple defects.

Out of 36 children in group C, $3(8 \cdot 2 \%)$ had a birthweight $2 \mathrm{SD}$ or more below the mean for gestational age, sex, and birth rank; groups A and B

TABLE

Mean $( \pm S E)$ and $S D$ of birthweight, head circumference, and weight SDS at follow-up

\begin{tabular}{|c|c|c|c|c|c|c|c|c|c|}
\hline & \multicolumn{3}{|c|}{ Birthweight SDS } & \multicolumn{3}{|c|}{ Head circumference SDS } & \multicolumn{3}{|c|}{ Weight SDS (follow-up) } \\
\hline & No. & Mean $\pm \mathbf{S E}$ & SD & No. & Mean $\pm S E$ & SD & No. & Mean $\pm \mathbf{S E}$ & SD \\
\hline
\end{tabular}

^Statistically different from zero $(P<0.05)$.

+ Statistically different from zero $(P<0.001)$.

$¥$ Statistically different from zero $(P<0.01)$.

SDS, Standards Deviation Scores. 

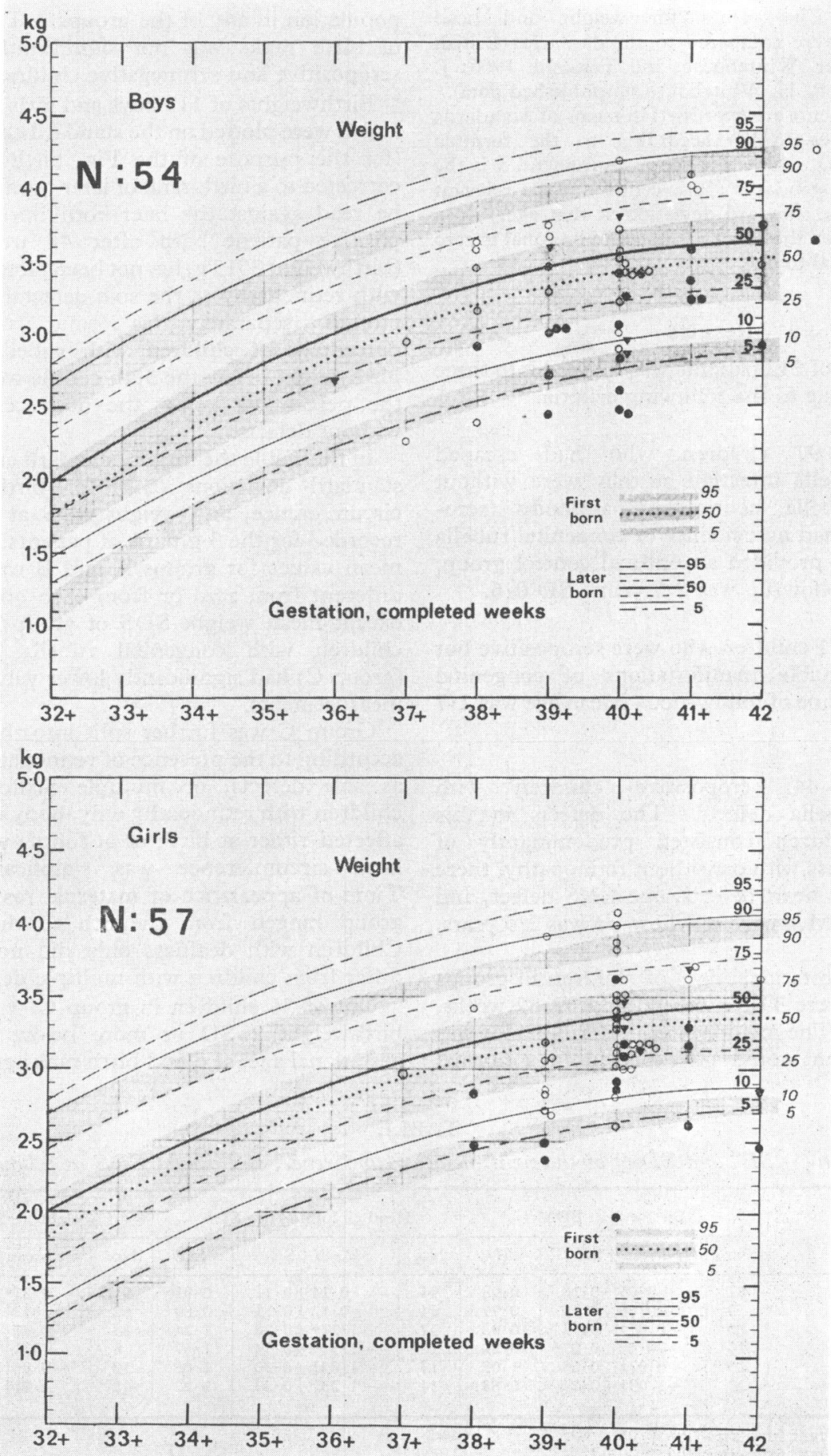

FIG.-Birthweights cf seropositive children (groups $B$ and $C$ ). Retinofathy $\boldsymbol{\nabla}$, other defects $\bigcirc$, no defects $\bigcirc$. 
had $1(1 \cdot 1 \%)$ and none $(0 \%)$, respectively. In group C, 7 children $(16 \cdot 2 \%)$ had a head circumference 2 SD or more below the mean for their age; 3 of these had deafness, 2 retinopathy, and the remainder had both defects. In groups $\mathbf{A}$ and $\mathbf{B}$ there were only 1 $(1 \cdot 5 \%)$ and $2(2 \cdot 1 \%)$ children, respectively, with a head circumference 2 SD or more below the mean. Weight at follow-up was 2 SD below the mean in 3 $(11 \%), 2(3 \cdot 2 \%)$, and $1(1 \cdot 8 \%)$ children from groups $\mathrm{C}, \mathrm{A}$, and $\mathrm{B}$, respectively.

Group B children (seropositive without defects) were further divided into those whose mothers had rubella before the 15th week of pregnancy and those who had it between 15 and 24 weeks. The mean SDS of the three measurements for the two subgroups were calculated separately and in neither group did the means depart significantly from zero.

\section{Discussion}

The results of this study confirm, using more accurate standards, the findings on birthweight of children with congenital rubella already reported (Peckham, 1972). In the seropositive cases of congenital rubella, fetal growth was not retarded in cases that lacked clinical manifestations of the infection. Previous reports on the subject are consistent with our findings. During the rubella epidemic of 1951 in Britain (Manson, Logan, and Loy, 1960), the mean birthweight of children with congenital rubella syndrome was lower than that of children exposed to maternal infection during the first trimester but with no congenital defects; the incidence of children with birthweights under $2500 \mathrm{~g}$ in this last group was similar to the controls. The same results were reported during epidemics in the U.S.A. (Sever, Nelson, and Gilkeson, 1965) and in Sweden (Lundstrom, 1962). In this last survey, however, the mean birthweight of children with no defects was significantly lower than that of the controls. As these studies were based on clinical criteria of diagnosis, seronegative cases could not be distinguished from seropositive ones without congenital defects, both being regarded as possibly infected. The serological means of diagnosis in our sample, together with the clinical evaluation of congenital defects at preschool age, allow the recognition of children infected in utero who were otherwise normal and the detection of late manifestations of congenital rubella such as deafness. In studies in which the diagnosis of rubella infection was based on serological grounds, it has been reported that children whose only defect is deafness may have a birthweight within normal limits (Gumpel, Hayes, and Dudgeon, 1971); furthermore, the mean birthweight of rubella deaf children did not differ significantly from the mean for children who were deaf for other reasons. However, when compared to standards for normal children, the mean birthweight of our deaf patients was significantly reduced. There was found to be no significant difference in birthweight between children with deafness and multiple defects in our sample, but this may be due to the fact that the multiply-handicapped children were not of the severity reported by Gumpel (1972) who found that multiply-handicapped and severely damaged children had a lower birthweight for gestational age.

The present results show that the fetus may escape growth curtailment resulting from infection, even if this occurs during the teratogenic period. This applies both to growth in body weight and in head circumference. Microcephaly has not been encountered as a sole manifestation of congenital rubella.

The fact that in group $\mathrm{C}$ weight at follow-up was comparably low to weight at birth suggests the absence of catch-up growth (Prader, Tanner, and Von Harnack, 1963) in these patients between birth and the time of the examination. Naeye and Blanc (1965) showed that the effect of rubella virus on the fetus was to reduce the number of cells rather than the size of cells, hence causing certain organs to be small. If virus replication in the fetus is widespread it is therefore understandable that there is an overall growth retardation. In small-for-dates children, for example, a similar lack of cell multiplication in a critical period accounts for the persisting lack of adipose tissue in later childhood (Brook, 1972).

In patients with rubella retinopathy as a single defect, one must presume that the intrauterine viral infection has impaired growth of the CNS without affecting total body weight; the reverse situation, i.e. growth impairment in the absence of other malformations, was not observed. Gruenwald (1963) and Warkany, Monroe, and Sutherland (1961) have indicated the existence of subnormal growth in utero as a sole form of maldevelopment, but this does not seem to occur in congenital rubella.

We thank Professors J. M. Tanner and J. A. Dudgeon for advice, and the British Council for financial support.

\section{REFERENCES}

Brook, C. G. D. (1972). Evidence for a sensitive period in adiposecell replication in man. Lancet, $2,624$.

Dudgeon, J. A., Butler, N. R., and Plotkin, S. A. (1964). Further serological studies on the rubella syndrome. British Medical Fournal, 2, 155.

Gruenwald, P. (1963). Chronic foetal distress and placental insufficiency. Biology of the Neonate, 5, 215.

Gumpel, S. M. (1972). Clinical and social status of patients with congenital rubella. Archives of Disease in Childhood, 47, 330. 
Gumpel, S. M., Hayes, K., and Dudgeon, J. A. (1971). Congenital perceptive deafness: role of intrauterine rubella. British Medical fournal, 2, 300.

Lundstrom, R. (1962). Rubella during pregnancy. Acta Paediatrica Scandinavica, 51, Suppl. 133, 1.

McDonald, J. C., and Peckham, C. S. (1967). Gammaglobulin in prevention of rubella and congenital defect: a study of 30,000 pregnancies. British Medical fournal, 3, 633.

Manson, M. M., Logan, W. P. D., and Loy, R. M. (1960). Rubella and Other Virus Infections During Pregnancy. Ministry of Health Reports on Public Health and Medical Subiects, No. 101. H.M.S.O., London.

Naeye, R. L., and Blanc, W. (1965). Pathogenesis of congenital rubella. Fournal of the American Medical Association, 194, 1277.

Peckham, C. S. (1972). Clinical and laboratory study of children exposed in utero to maternal rubella. Archives of Disease in Childhood, 47, 571.

Prader, A., Tanner, J. M., and Von Harnack, G. A. (1963). Catchup growth following illness or starvation. Fournal of Pediatrics, 62,646 .
Sever, J. L., Nelson, K. B., and Gilkeson, M. R. (1965). Rubella epidemic 1964. I. Effect on 6,000 pregnancies. American Fournal of Diseases of Children, 110, 395.

Tanner, J. M., and Thomson, A. M. (1970). Standards for birthweight at gestation periods from 32 to 42 weeks allowing for maternal height and weight. Archives of Disease in Childhood, 45, 566.

Tanner, J. M. Whitehouse, R. H., and Takaishi, M. (1966). Standards from birth to maturity for height, weight, height velocity, and weight velocity: British children 1965 . Archives of Disease in Childhood, 41, 454 and 613.

Warkany, J., Monroe, B. B., and Sutherland, B. S. (1961). Intrauterine growth retardation. American fournal of Diseases of Children, 102, 249.

Correspondence to Dr. Catherine S. Peckham, Department of Microbiology, The Hospital for Sick Children, Great Ormond Street, London WC1N 3JH.

The following articles will appear in future issues of this journal:

Increased incidence of lymphoreticular aggregates in the lungs of children found unexpectedly dead. J.L. Emery and F. Dinsdale.

Aspects of Epstein-Barr virus infection in childhood. R. N. P. Sutton, S. D. Marston, E. J. P. Almond, and R. T. D. Emond.

Urinary excretion of calcium and magnesium in children. S. Ghazali and T. M. Barratt.

Evidence for early impairment of verbal intelligence in Duchenne muscular dystrophy. G. G. Marsh, and T. L. Munsat.

Personal practice: Management of severe viral bronchiolitis and severe acute asthma. P. D. Phelan and J. G. Stocks. Neonatal hypoglycaemia with congenital malformation of the pancreatic islets. D. C. Davidson, M. J. Blackwood, and E. G. Fox.

Urinary hydroxyproline in children with growth hormone deficiency: clinical value in diagnosis and prognosis. B. A. Wharton, G. Brown, P. H. W. Rayner, G. Howells, and C. A. Pennock.

Idiopathic arterial calcification in infancy. T. Bird. 